\title{
PERANCANGAN SISTEM INFORMASI PENJUALAN, PRODUKSI DAN PERSEDIAAN PADA PT TRIWARNA EKA MULTIMEDIA
}

\author{
Stephanie Surja; Lius Steven Sanjaya \\ Jurusan Sistem Informasi, School of Information Systems, BINUS University \\ Jl. KH. Syahdan No. 9, Palmerah, Jakarta Barat 11480 \\ surjastephanie@gmail.com; liusstevens@gmail.com
}

\begin{abstract}
The idea to design an information system in PT Triwarna Eka Multimedia arises because of the current information system is still very traditional and it has an enormous dependency to physical data. Designing of an information system in PT Triwarna Eka Multimedia is aimed to identify the organization needs in managing their business process operational related to current data of sales, production and inventory. The result from those processes is aimed to build an integrated system that can meet all of the organization's needs in running their daily business process and facing the rivalry from the competitors. The method used in this paper is a survey, literature review, and analysis of current business processes in the company These needs will be documented by using unified modeling language. This information system makes all the current operational business activities easier with the more enhanced automation than the previous information system. This system will also minimize the data lost and human error, which is usually cause by the manual process and storage data of physical data.
\end{abstract}

Keywords: analysis and design, information system, sales, production, inventory

\begin{abstract}
ABSTRAK
Munculnya ide untuk merancang sebuah system informasi di PT Triwarna Eka Multimedia lebih dikarenakan sistem informasi yang ada sekarang masihlah bersifat tradisional dan sangat bergantung sekali dengn data-data yang sifatnya fisik. Perancangan sistem informasi di PT Triwarna Eka Multimedia bertujuan untuk mengidentifikasikan kebutuhan-kebutuhan perusahaan dalam pengelolaan operasional proses bisnis mereka yang terkait dengan data penjualan, produksi, dan persediaan yang berjalan. Hal ini bertujuan agar dapat tercipta sebuah sistem yang terintegrasi yang dapat menjawab seluruh kebutuhan perusahaan di dalam menjalankan operasional bisnisnya dan menghadapi persaingan dari para kompetitor. Metode yang digunakan dalam penulisan makalah ini adalah survei, tinjauan pustaka, serta analisis proses bisnis berjalan yang ada sekarang di perusahaan. Hasil analisa terhadap seluruh kebutuhan perusahaan tersebut akan didokumentasikan dengan menggunakan metode unified modeling language. Dengan adanya sistem informasi ini maka seluruh kegiatan operasional bisnis di dalam perusahaan dipermudah dengan otomasi yang lebih sempurna dibandingkan dengan sistem yang sebelumnya, di samping juga meminimalisir kehilangan atau kesalahan data yang sering terjadi diakibatkan dari penyimpanan data transaksi yang dilakukan dalam bentuk fisik dan tidak teroganisir.
\end{abstract}

Kata kunci: Perancangan, sistem informasi, penjualan, produksi, persediaan 


\section{PENDAHULUAN}

Masyarakat luas telah mengenal teknologi baik secara implicit ataupun explicit. Teknologi hadir guna memudahkan pengguna dalam hal menyelesaikan semua aktivitas-aktivitas yang ada. Maka bukan hal yang baru bila masyarakat di era digital ini sangat akrab dengan penggunaan personal computer atau laptop, internet, e-commerce, e-business, dan lainnya. PT TRIWARNA EKA MULTIMEDIA adalah sebuah perusahaan percetakan di Jakarta yang menerapkan sistem proses bisnis secara tradisional, dimana ini membutuhkan biaya, waktu dan tenaga kerja yang lebih banyak. Melihat perkembangan zaman yang pesat, perusahaan menginginkan sebuah sistem informasi yang dapat mengatasi proses bisnis pada penjualan, produksi, dan persediaan.

Dilihat dari cara PT TRIWARNA EKA MULTIMEDIA menjalankan bisnis, letak permasalahan perusahaan ini terletak pada proses bisnis itu sendiri yang masih bersifat tradisional, di mana masih bergantung pada catatan fisik dan masih menggunakan kertas sebagai media untuk menyimpan data-data penting yang diperlukan.Berbicara mengenai teknologi, dunia bisnis selalu menjadi kaitan pembicaraan yang menyenangkan untuk dibahas. Masyarakat di era digital saat ini lebih menyukai proses bisnis modern, dimana semua aspek bisnis yang ada melibatkan penggunaan teknologi. Masyarakat sudah meninggalkan proses bisnis tradisional yang lebih banyak menyita waktu dan tenaga. Bisnis modern selalu bersifat dinamis, bergerak mengikuti perkembangan zaman, dimana didalamnya teknologi memiliki peranan yang besar.

Mengingat permasalahan dari perusahaan ini terletak di dalam sistem yang mana masih bersifat traditional dan masih sangat bergantung dengan data-data yang disimpan dalam bentuk fisik. Maka direncanakan agar sistem informasi yang akan dianalisa dan dirancang ini dapat menyelesaikan masalah tersebut dengan cara bahwa sebuah sistem informasi bukan hanya mengenai input dan output namun sistem informasi tersebut dapat membantu perusahaan di dalam mengambil keputusan penting. Contohnya dengan menggunakan fitur dashboard atau grafik penjualan atas produk-produk mereka. Data-data yang masih disimpan secara fisik tidak lagi dicetak melainkan disimpan saja di dalam sistem dan dapat diambil kembali ketika mereka membutuhkan hal tersebut.

Menurut Hongren (2003), produksi adalah memperoleh, mengkoordinasikan, dan mengumpulkan sumber daya untuk menghasilkan sebuah produk atau memberikan suatu layanan. Menurut Bodnar dan Hopwood (2000), sistem informasi produksi adalah sistem informasi manajemen yang menyediakan informasi yang digunakan oleh fungsi produksi.

Penjualan merupakan sebuah proses di mana kebutuhan pembeli dan kebutuhan penjual dipenuhi, melalui antar penukaran informasi dan kepentingan. (Kotler, Kotler, \& Kelvin, 2006). Menurut Alianto (2011), konsep penjualan mempunyai perspektif dari dalam ke luar, yang berarti dimulai dari saat di pabrik, berfokus pada produk yang sudah tersedia dan melakukan promosi untuk menghasilkan penjualan yang dapat menghasilkan keuntungan. Sedangkan sistem informasi penjualan berupa kegiatan yang meliputi transaksi penjualan barang dan jasa baik secara tunai maupun non tunai dengan tujuan mendapatkan laba.

Sistem Persediaan merupakan integrasi dari proses bisnis yang merupakan kunci dimulai dari end user melalui supplier yang menawarkan produk, layanan, dan informasi untuk memberikan nilai lebih bagi pelanggan dan pihak lainnya (Chan \& Qi, 2003). Dengan adanya Sistem Persediaan ini, diharapkan seluruh proses bisnis perusahaan dapat berjalan dengan lancar karena seluruh sumber daya yang dibutuhkan selalu tersedia. Menurut Chen \& Paulraj (2004), di dalam sebuah rantai sistem persediaan harus terdapat hubungan yang baik antara pembeli dan penyedia (buyer-supplier). Sistem persediaan ini secara tidak langsung dapat dikatakan bukanlah sebuah entitas yang dapat berdiri sendiri, melainkan tidak dapat dipisahkan sebagai suatu bisnis individual. 


\section{METODE}

Metode yang digunakan dalam penulisan makalah ini adalah survey, tinjauan pustaka, serta analisis proses bisnis berjalan yang ada sekarang di perusahaan. Dari hasil survey dan analisis tersebut didapatkan kebutuhan-kebutuhan perusahaan yang perlu diaplikasikan dalam sistem informasi yang nantinya akan dibangun. Dokumentasi dari hasil analisis menggunakan unified modeling language yang didasarkan pada unified process disciplines (Satzinger, 2005).

\section{HASIL DAN PEMBAHASAN}

\section{Proses Bisnis Berjalan}

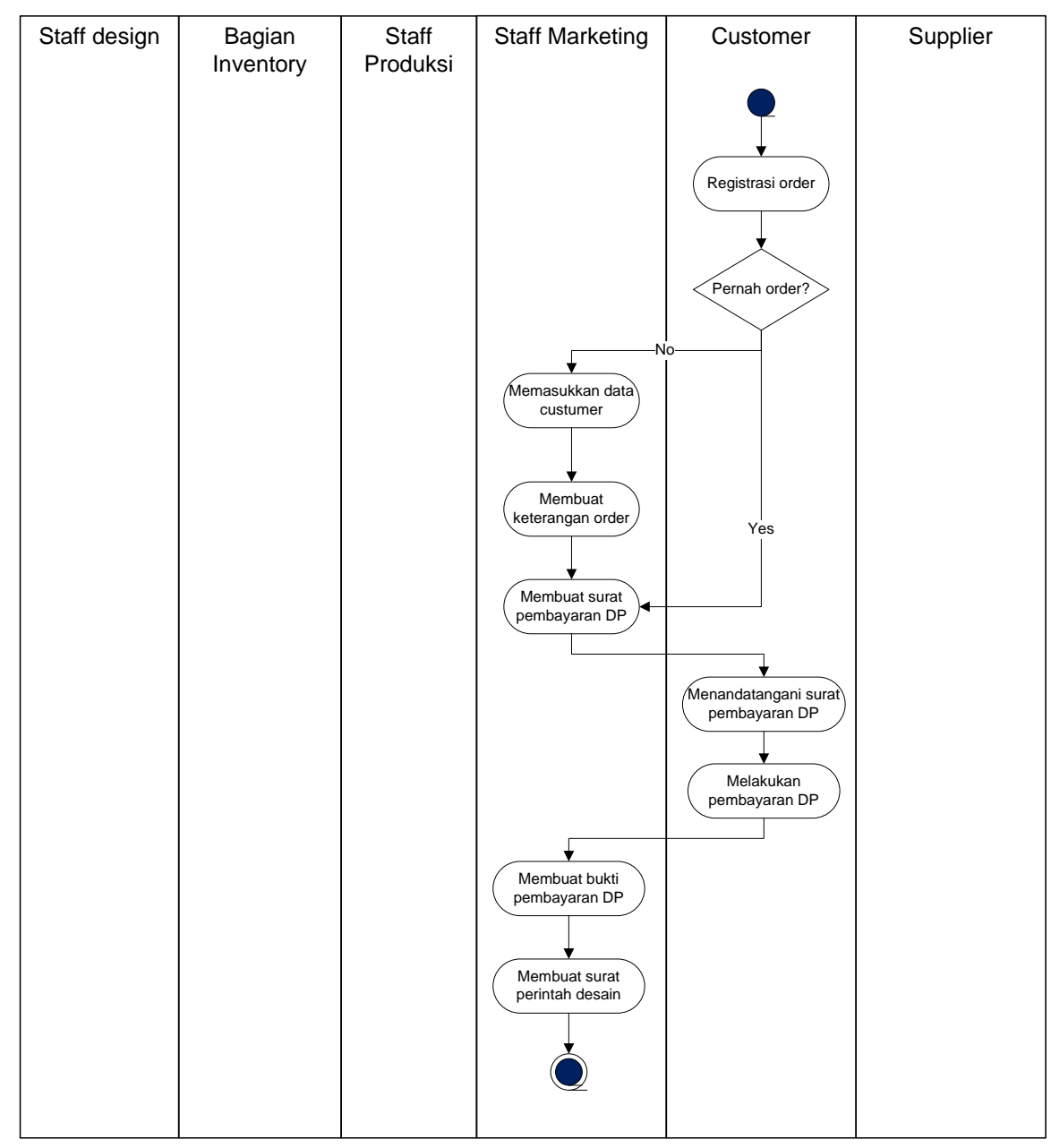

Gambar 1 Activity Diagram Proses Penjualan Manual 


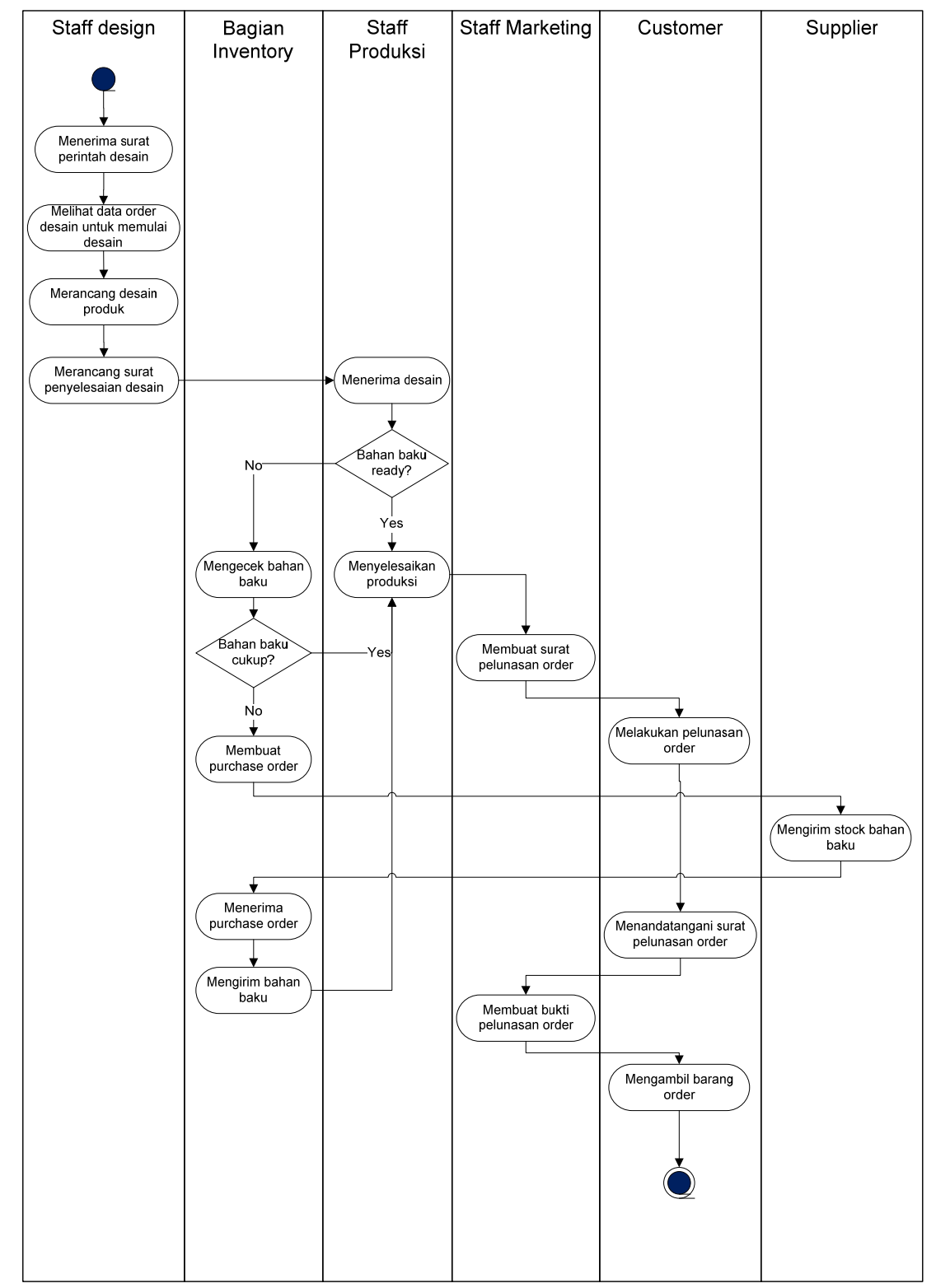

Gambar 2 Activity Diagram Proses Inventory dan Proses Produksi Manual

Proses Penjualan : Jika Customer baru, Marketing Staff akan mencatat data diri Customer berupa nama perusahaan, alamat perusahaan, contact person, nomer telpon perusahaan, dan email. Kemudian Marketing Staff mencatat keterangan order yang isinya berupa tanggal order, order, detail order, keterangan (permintaan khusus dari customer), jumlah pembayaran, dan deadline project.

Proses Inventory : Inventory Staff menerima catatan Order untuk melihat barang apa saja yang perlu disediakan dan dikirim ke Production Staff. Kemudian Inventory Staff akan mengecek apakah barang yang diinginkan masih mencukupi atau kurang. Apabila barang yang dibutuhkan untuk produksi kurang, Marketing Staff akan membuat Purchase Order kepada Supplier. 
Proses Produksi : Production Staff akan melihat kembali catatan data Customer dan catatan Order dari Customer yang diberikan oleh Marketing Staff. Production Staff akan memulai produksi sesuai catatan Order dari Customer apabila barang sudah disediakan oleh Inventory Staff.

\section{Permasalahan yang Dihadapi}

Proses Penjualan : Tidak teroganisirnya record penjualan karena masih menggunakan sistem manual. Tidak mempunyai database untuk menapung record tersebut sehingga tidak dapat mengelola data dengan baik dan record yang masih tidak terorganisir menyebabkan gagalnya pengelolaan informasi dan risiko miss communication antar divisi.

Proses Inventory : Tidak terorganisirnya record pembelian barang dari Supplier dan persediaan barang di gudang karena masih menggunakan pegecekan manual. Sehingga menyebabkan macetnya proses produksi karena barang yang dibutuhkan untuk produksi sering kali tidak tersedia.

Proses Produksi : Proses bisnis dilakukan secara tradisional, dimana ini membutuhkan biaya, waktu dan tenaga kerja yang lebih banyak. Selain itu, proses bisnis masih bergantung pada catatan fisik, yaitu kertas sebagai media untuk menyimpan data-data yang diperlukan. Jika terjadi human error, kerusakan pada data yang berupa kertas, maka proses produksi dan proses bisnis pada perusahaan akan terhambat.

\section{Usulan Pemecahan Masalah}

Proses Penjualan : Jika Customer baru, Marketing Staff akan input data diri Customer ke dalam form aplikasi data diri yang isinya berupa nama, nama perusahaan, alamat perusahaan, nomor telepon perusahaan, email perusahaan dan keterangan order dalam form aplikasi keterangan order yang isinya berupa tanggal order, order, detail order, keterangan (permintaan khusus dari customer), jumlah pembayaran, dan deadline project.

Proses Inventory : Inventory Staff menerima tampilan Order yang berupa list barang apa saja yang dibutuhkan untuk proses produksi. Kemudian Inventory Staff mengecek persediaan barang di dalam list stock persediaan barang. Jika barang yang dibutuhkan masih mencukupi, Inventory Staff akan mengirim langsung kepada Production Staff. Jika barang yang dibutuhkan kurang, Marketing Staff akan membuat Purchase Order kepada Supplier.

Proses Produksi : Production Staff akan membuka Form Laporan Produksi untuk mengecek kembali barang yang digunakan apakah ada penambahan bahan baku yang digunakan atau tidak. 
Activity Diagram: Usulan Proses Bisnis

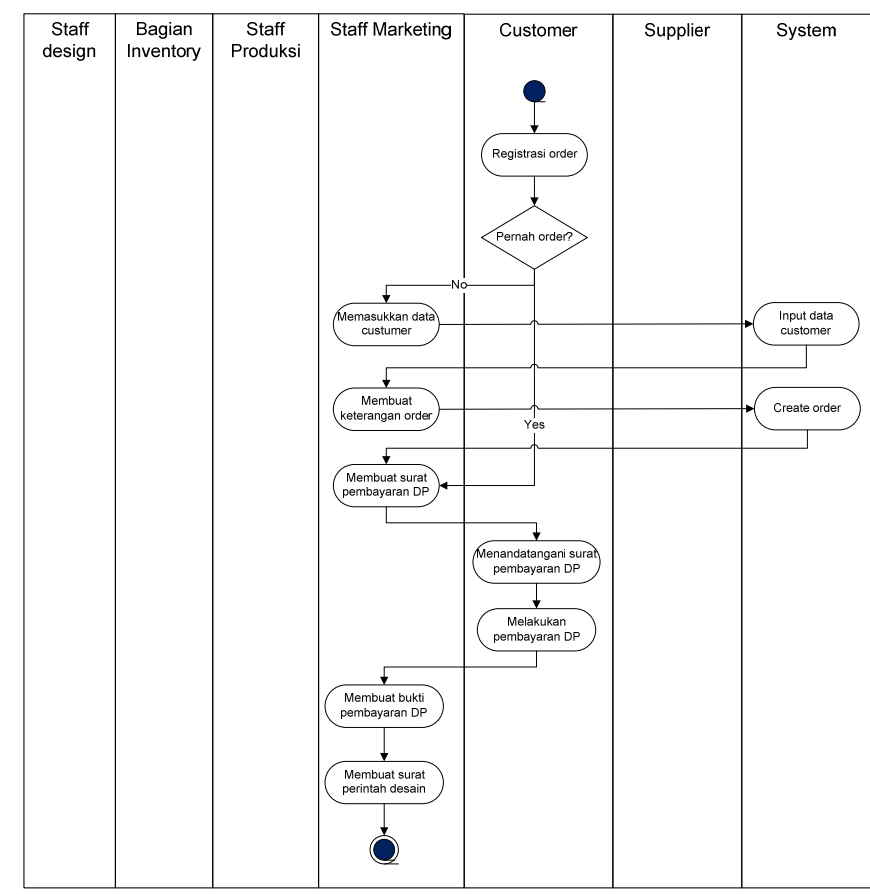

Gambar 3 Activity Diagram untuk Proses Penjualan System

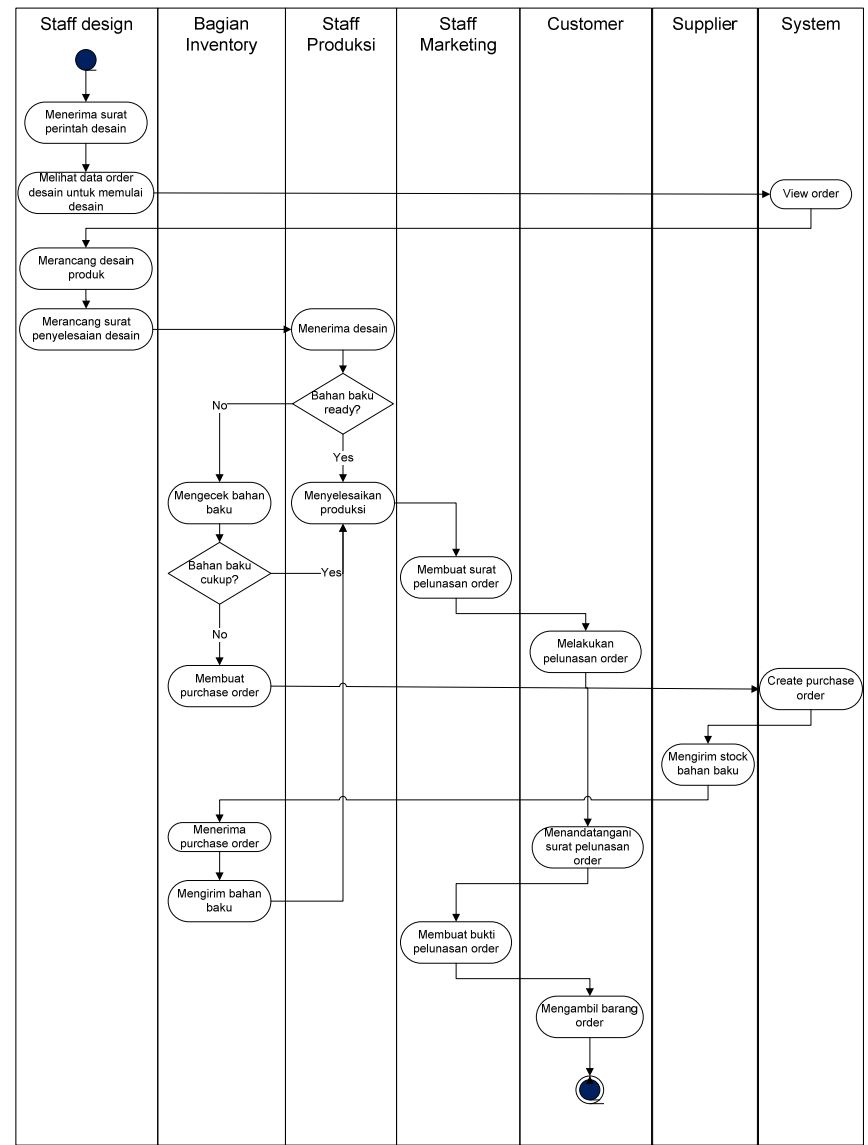

Gambar 4 Activity Diagram Proses Inventory System dan Proses Produksi System 


\section{Use Case Diagram}

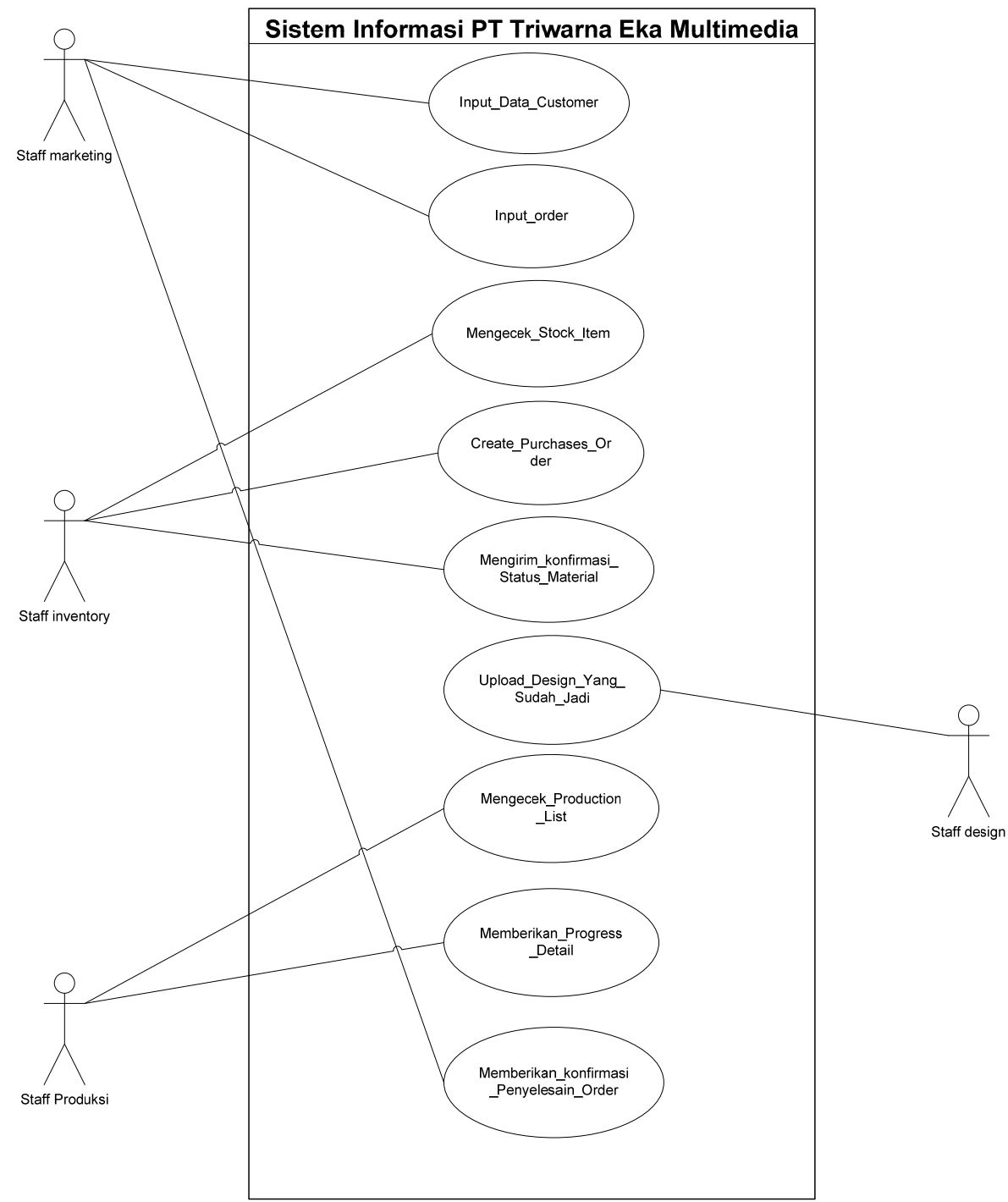

Gambar 5 Use Case Diagram 


\section{Domain Class Diagram}

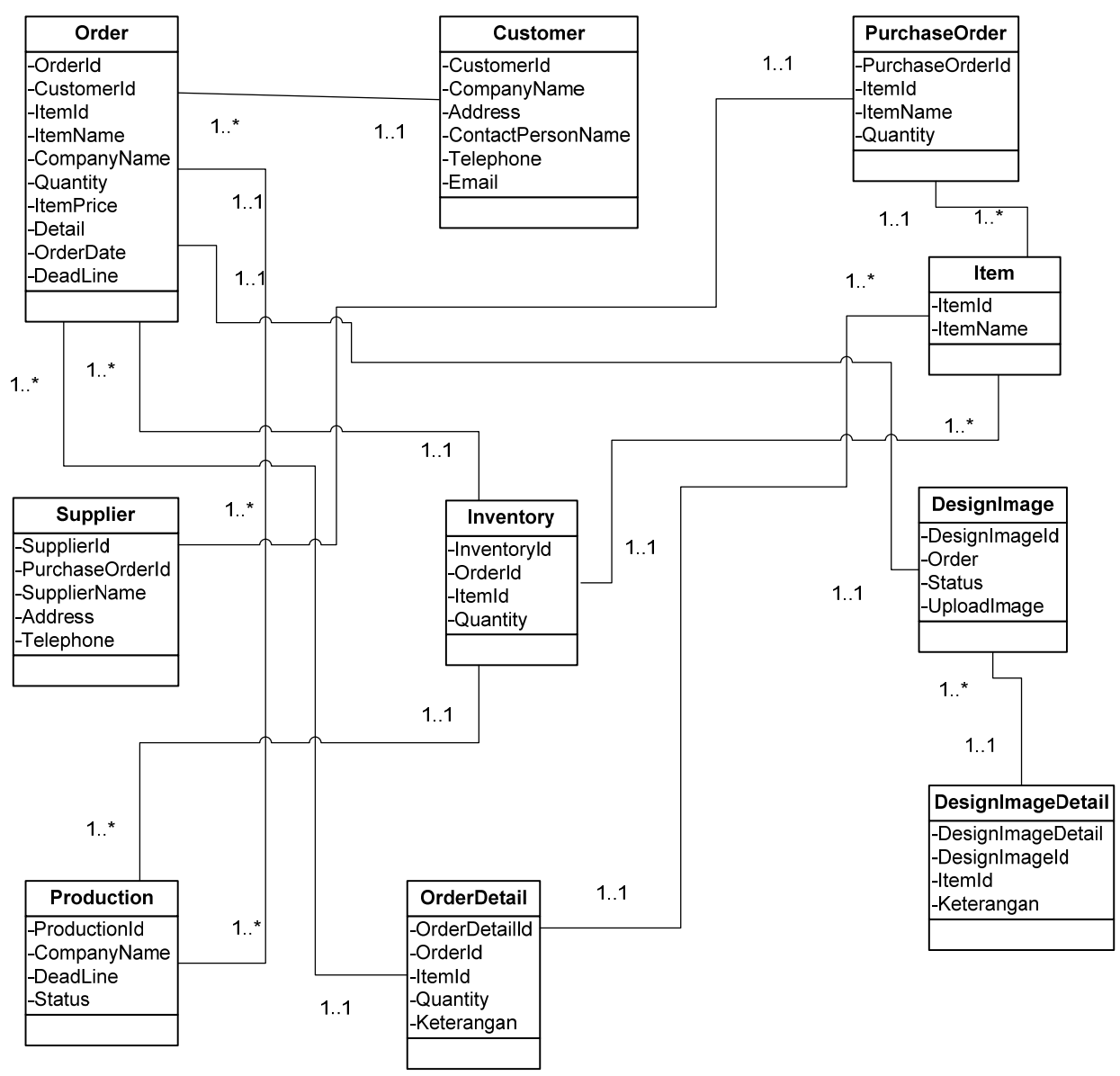

Gambar 6 Domain Class Diagram

\section{Use Case Description: Fully Developed Description}

Tabel 1 Use Case Description

\begin{tabular}{|c|c|c|}
\hline Use Case Name: & \multicolumn{2}{|l|}{ Input data customer } \\
\hline Scenario: & \multicolumn{2}{|l|}{ Input data cusotmer } \\
\hline Triggering Event: & \multicolumn{2}{|l|}{ Adanya data order } \\
\hline Brief Description: & \multicolumn{2}{|c|}{ Adanya data order,jika ingin mengiunput harus meegisi form data customer } \\
\hline Actors: & \multicolumn{2}{|l|}{ Marketing Staff } \\
\hline Related Usecase: & \multicolumn{2}{|l|}{-} \\
\hline Stake holder: & \multicolumn{2}{|c|}{ Staff markerting membutuhkan data customer untuk menginput kedalam sistem } \\
\hline Precondition: & \multicolumn{2}{|c|}{ Harus ada data order dari customer } \\
\hline Postcondition: & \multicolumn{2}{|l|}{ Input data customer terbuat } \\
\hline \multirow[t]{4}{*}{ Flow of Event: } & Actor & System \\
\hline & 1.Customer datang kekantor untuk mengisi & \\
\hline & order & 2.1Start input data customer \\
\hline & 2.Input data customer & \\
\hline
\end{tabular}


Tabel 2 Use Case Description

\begin{tabular}{|c|c|}
\hline Use Case Name: & Input order \\
\hline Scenario: & Input order \\
\hline Triggering Event: & Adanya data customer \\
\hline Brief Description: & Adanya data order,jika ingin mengiunput harus meegisi form data order \\
\hline Actors: & Marketing Staff \\
\hline Related Usecase: & - \\
\hline Stake holder: & Marketing Staff membutuhkan data order untuk menginput kedalam sistem \\
\hline Precondition: & Harus ada data customer dari order \\
\hline Postcondition: & Input order terbuat \\
\hline \multirow[t]{2}{*}{ Flow of Event: } & System \\
\hline & $\begin{array}{l}\text { 1. Membuat keterangan order ke form order } \\
\text { 2. input order }\end{array}$ \\
\hline Exception Condition: & 2.1 Jika tidak ada input order tidak ada customer untuk bernegosiasi order \\
\hline
\end{tabular}

Tabel 3 Use Case Description

\begin{tabular}{|c|c|}
\hline Use Case Name: & Mengecek stock item \\
\hline Scenario: & Mengecek stock item \\
\hline Triggering Event: & Adany purchases order \\
\hline Brief Description: & Adany pruchses order,jika ingin mengecek harus ada stock item \\
\hline Actors: & Inventory Staff \\
\hline Related Usecase: & - \\
\hline Stake holder: & $\begin{array}{l}\text { Inventory Staff membutuhkan data pirchases order untuk mengecek stock item di } \\
\text { dalam sistem }\end{array}$ \\
\hline Precondition: & Harus ada data purchases order dari stock item \\
\hline Postcondition: & Terjadinya pengecekan stock item \\
\hline \multirow[t]{2}{*}{ Flow of Event: } & Actor \\
\hline & $\begin{array}{l}\text { 1.1Start mengecek } \\
\text { stock item }\end{array}$ \\
\hline
\end{tabular}

\section{Tabel 4 Use Case Description}

\begin{tabular}{|c|c|}
\hline Use Case Name: & Create purchases order \\
\hline Scenario: & Create purchases order \\
\hline Triggering Event: & Stock item berkurang \\
\hline Brief Description: & Stock item berkurang,jika ingin membuat harus ada purchases order \\
\hline Actors: & Inventory Staff \\
\hline Related Usecase: & - \\
\hline Stake holder: & Inventory Staff membutuhkan stock item untuk create purchases order didalam sistem \\
\hline Precondition: & Harus ada item dari purchases order \\
\hline Postcondition: & Create purchases order terbuat \\
\hline \multirow[t]{2}{*}{ Flow of Event: } & Actor \\
\hline & 1.1Create purchases order \\
\hline Exception Condition: & 1.1 Jika tidak ada purchases oorder tidak ada stock item berkurang \\
\hline
\end{tabular}


Tabel 5 Use Case Description

\begin{tabular}{|c|c|}
\hline Use Case Name: & Mengirim konfirmasi Status material \\
\hline Scenario: & Mengirim konfirmasi Status material \\
\hline Triggering Event: & Produk sesusai standart produksi \\
\hline Brief Description: & $\begin{array}{l}\text { Produksi sesuai standart produksi,jika ingin mengirim harus ada konfirmasi } \\
\text { status material }\end{array}$ \\
\hline Actors: & Inventory Staff \\
\hline Related Usecase: & - \\
\hline Stake holder: & $\begin{array}{l}\text { Inventory Staff membutuhkan produk sesuai standart produksi untuk mengirim } \\
\text { konfirmasi status material didalam sistem }\end{array}$ \\
\hline Precondition: & Harus ada produk sesuai standart produksi dari pengorderan \\
\hline Postcondition: & Terjadinya pengiriman konfirmasi status material \\
\hline \multirow[t]{2}{*}{ Flow of Event: } & System \\
\hline & $\begin{array}{l}\text { 1.1Start mengirim konfirmasu } \\
\text { material }\end{array}$ \\
\hline Exception Condition: & - \\
\hline
\end{tabular}

Tabel 6 Use Case Description

\begin{tabular}{llc}
\hline Use Case Name: & Upload desain yang sudah jadi \\
Scenario: & Upload desain yang sudah jadi \\
Triggering Event: & Adanya order dari customer \\
Brief Description: & Adanya order dari customer,jia ingin mengupload harus ada desain yang sudah jadi \\
Actors: & Staff desain & \\
Related Usecase: & - & \\
Stake holder: & Staff design membutuhkan data order untuk mengupload desain yang susdah jadi \\
& didalam sisem & \\
Precondition: & Harus ada ada order dan customer & System \\
Postcondition: & Upload desain yang sudah jadi terbuat & Actor \\
\hline Flow of Event: & \multicolumn{1}{c}{ 1.Upload desain yang sudah jadi } \\
\end{tabular}

Tabel 7 Use Case Description

\begin{tabular}{|c|c|}
\hline Use Case Name: & Mengecek production list \\
\hline Scenario: & Mengecek production list \\
\hline Triggering Event: & Adanya data order yang ingin diproduksi \\
\hline Brief Description: & Adanya data order yang ingin diproduksi,jika ingin mengecek harus ada production list \\
\hline Actors: & Production Staff \\
\hline Related Usecase: & - \\
\hline Stake holder: & $\begin{array}{l}\text { Production Staff membutuhkan data order unutk mengecek production list didalam } \\
\text { sistem }\end{array}$ \\
\hline Precondition: & Harus ada data order dari production list \\
\hline Postcondition: & Terjadinya mengecek production list \\
\hline \multirow[t]{2}{*}{ Flow of Event: } & System \\
\hline & 1.1 Start mengecek production list \\
\hline
\end{tabular}


Tabel 8 Use Case Description

\begin{tabular}{llc}
\hline Use Case Name: & Memberikan progress detail \\
Scenario: & Memberikan progress detail & \\
Triggering Event: & Adanya permintaan daru customer \\
Brief Description: & Adanya permintaan daru customer,jika ingin memberikan harus ada progress detail \\
Actors: & Production Staff & \\
Related Usecase: & - & \\
Stake holder: & Production Staff membutuhkan permintaa dari custommer & \\
Precondition: & Harus ada permintaan dari customer & System \\
Postcondition: & Memberikan progress detail terbuat & Actor \\
\hline Flow of Event: & & 1.1 Start meberikan progress detail \\
\hline Exception Condition: & - & \\
\hline
\end{tabular}

Tabel 9 Use case Description

\begin{tabular}{|c|c|}
\hline Use Case Name: & Memberikan konfirmasi penyelesain order \\
\hline Scenario: & Memberikan konfirmasi penyelesain order \\
\hline Triggering Event: & Produk telah selesai \\
\hline Brief Description: & Produk telah selesai,jika memberikan harus ada konfirmasi penyelesain order \\
\hline Actors: & Marketing Staff \\
\hline Related Usecase: & - \\
\hline Stake holder: & $\begin{array}{l}\text { Marketing Staff membuktikan produk telah selseai untuk memberikan konfirmasi } \\
\text { penyelesain order didalam sistem }\end{array}$ \\
\hline Precondition: & Harus ada produk telah selesain dari Production Staff \\
\hline Postcondition: & Memberikan konfirmasi penyelesain order terbuat \\
\hline \multirow[t]{2}{*}{ Flow of Event: } & Actor \\
\hline & $\begin{array}{ll}\text { 1.Memberikan konfirmasi penyelesain order } & \begin{array}{l}1.1 \text { Start memberikan konfirmasi } \\
\text { penyelesain order }\end{array}\end{array}$ \\
\hline
\end{tabular}

\section{Sequence Diagram (SD)}

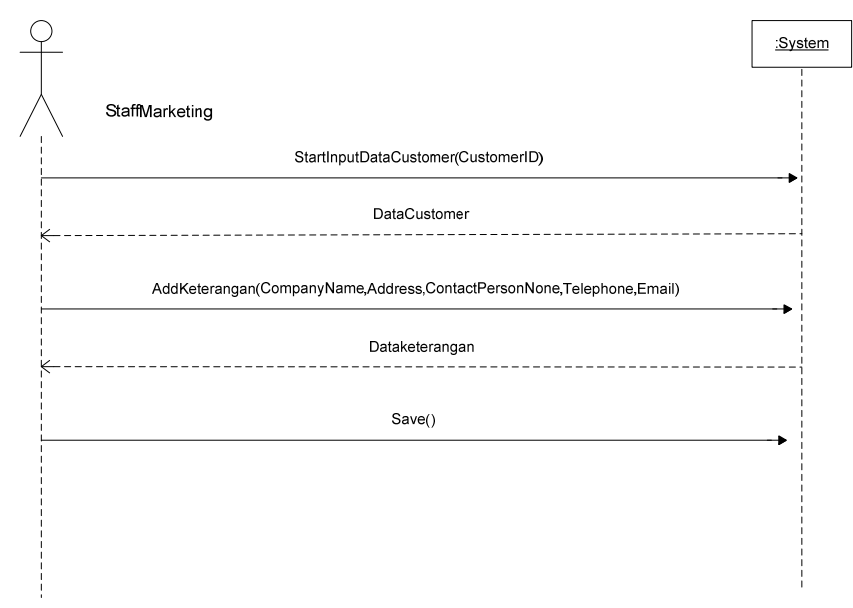

Gambar 7 System Sequence Diagram dari Input Data Customer 


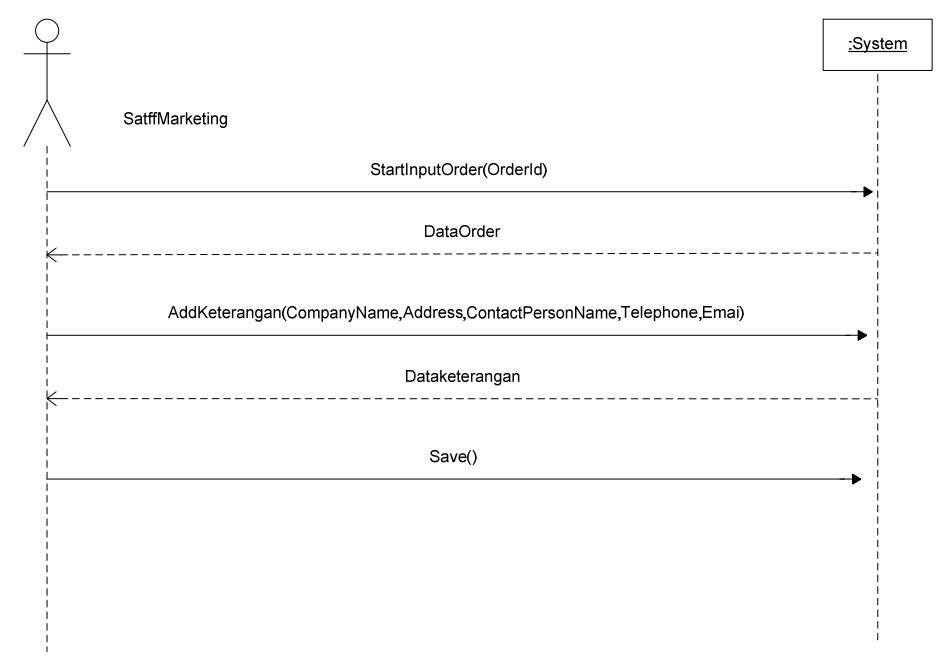

Gambar 8 System Sequence Diagram dari Input Order

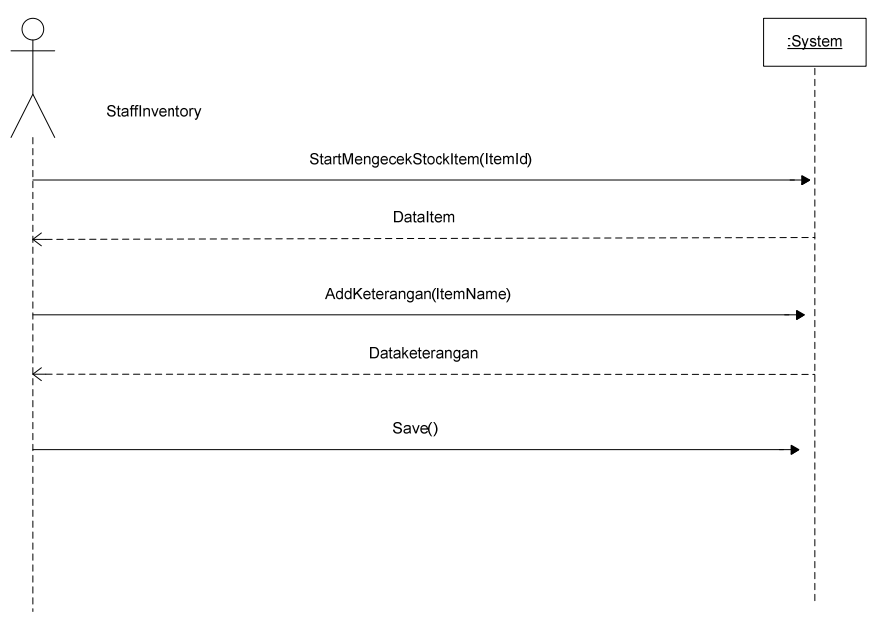

Gambar 9 System Sequence Diagram dari Mengecek Stock Item

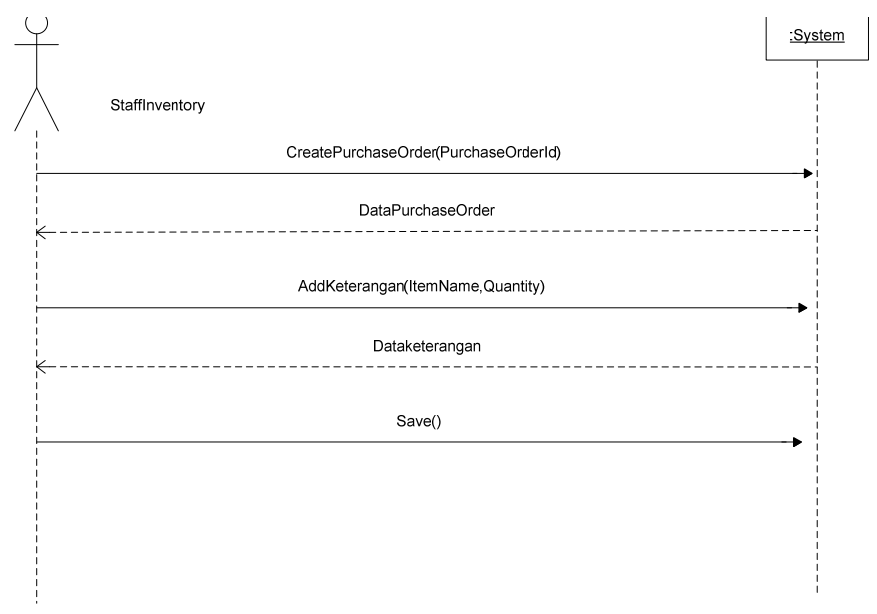

Gambar 10 System Sequence Diagram dari Create Purchase Order 


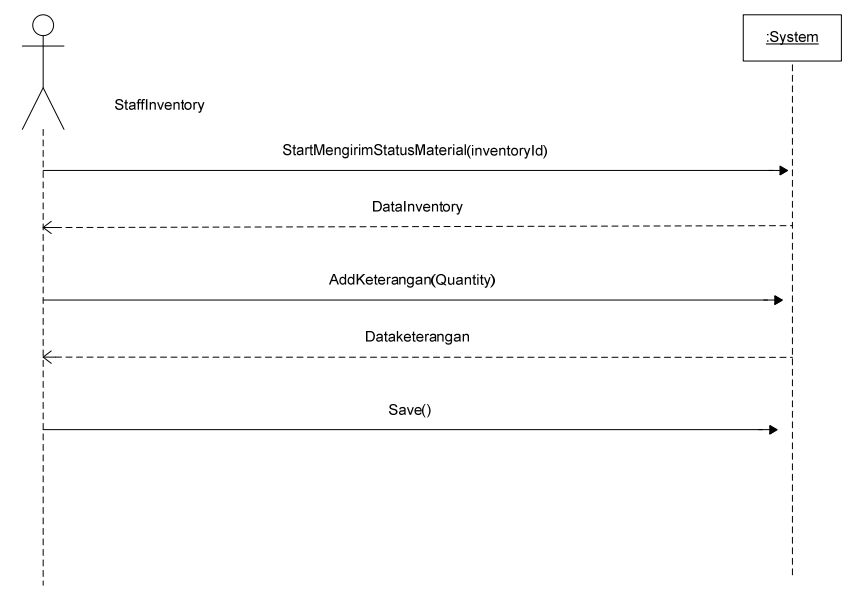

Gambar 11 System Sequence Diagram dari Mengirim Konfirmasi Status Material

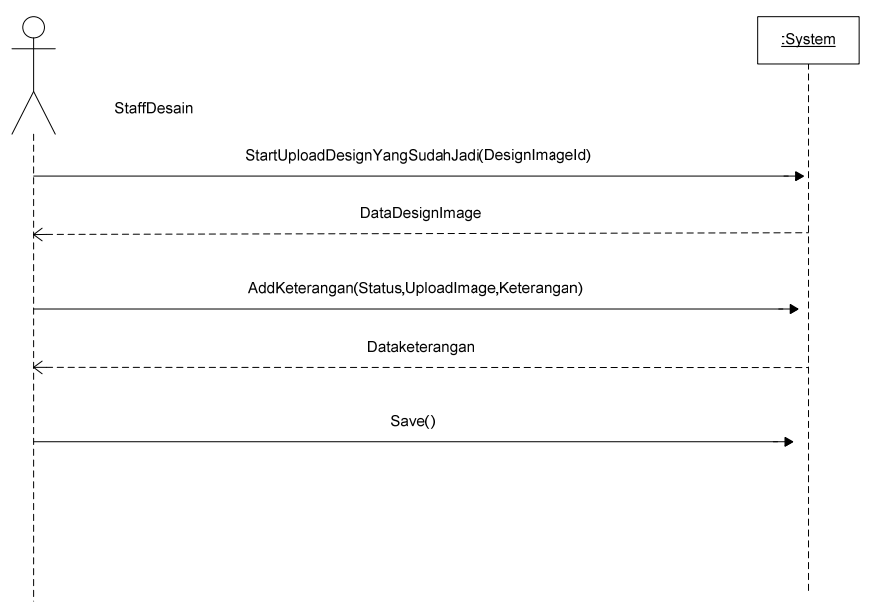

Gambar 12 Sytem Sequence Diagram dari Upload Desain yang Sudah Jadi

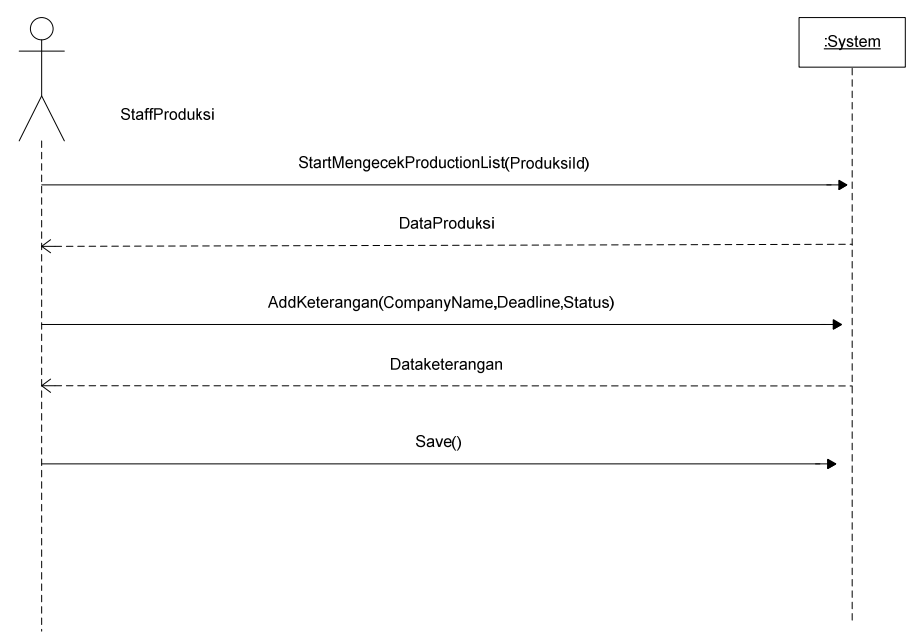

Gambar 13 System Sequence Diagram dari Mengecek Production List 


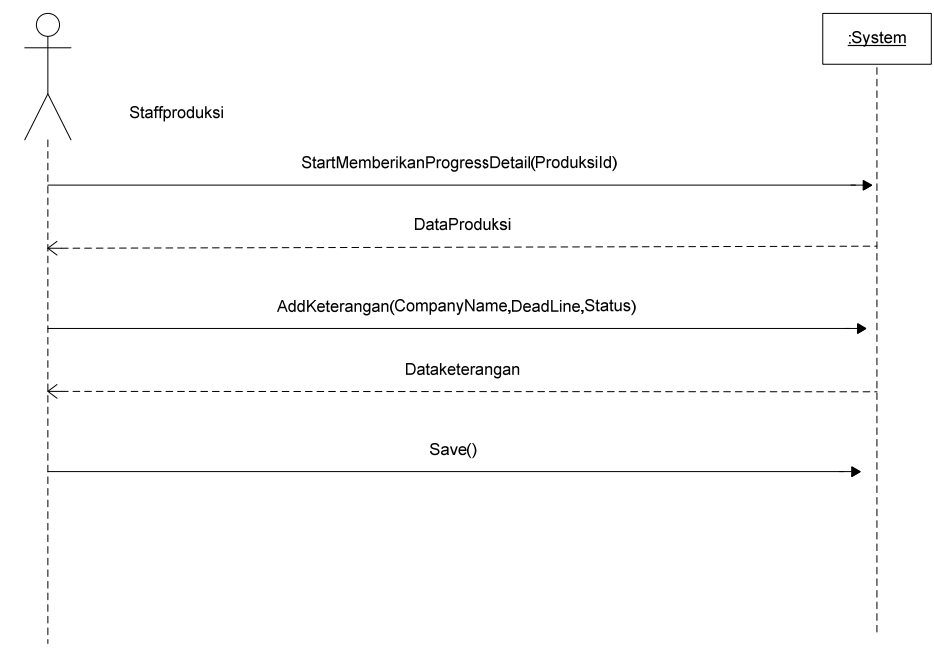

Gambar 14 System Sequence Diagram dari Memberikan Progress Detail

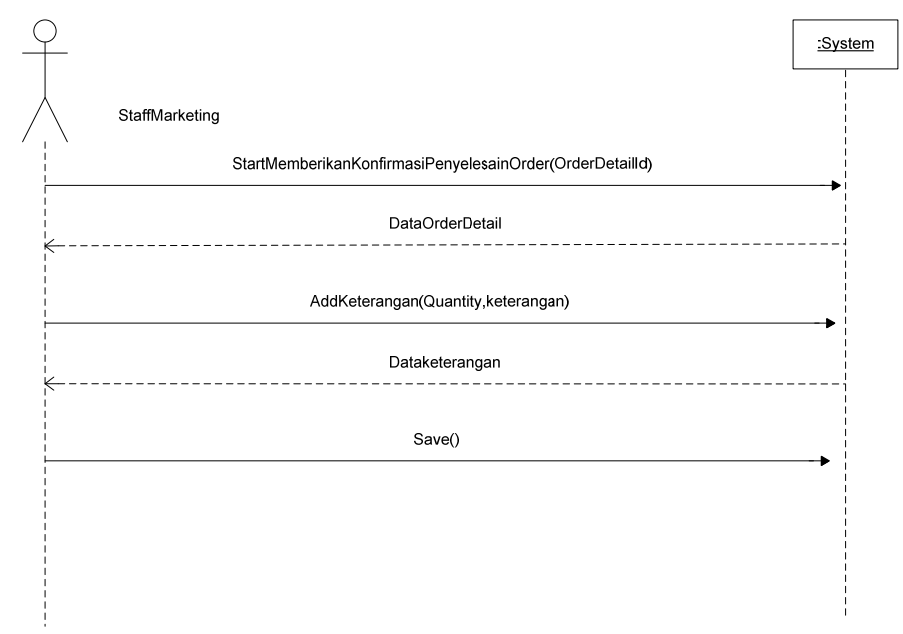

Gambar 15 System Sequence Diagram dari Memberikan Konfirmasi Penyelesaian Order

\section{State Chart Diagram}

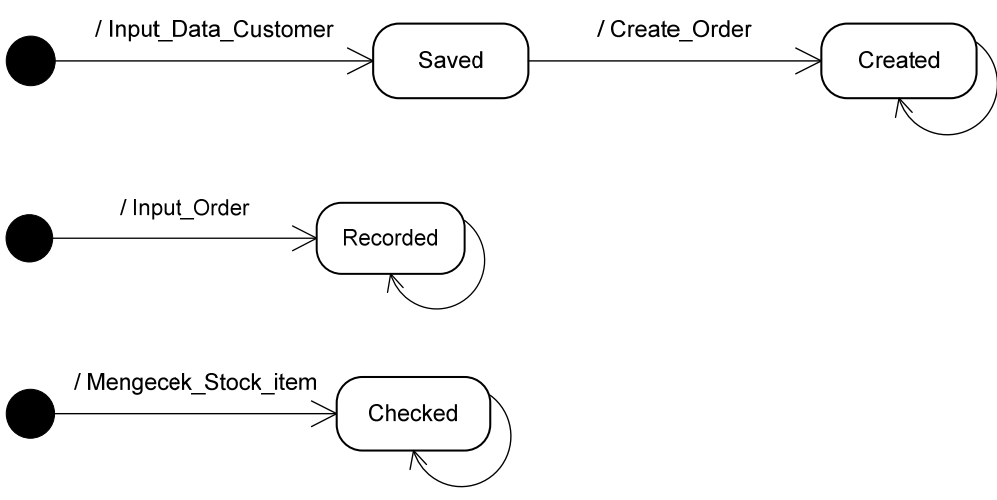




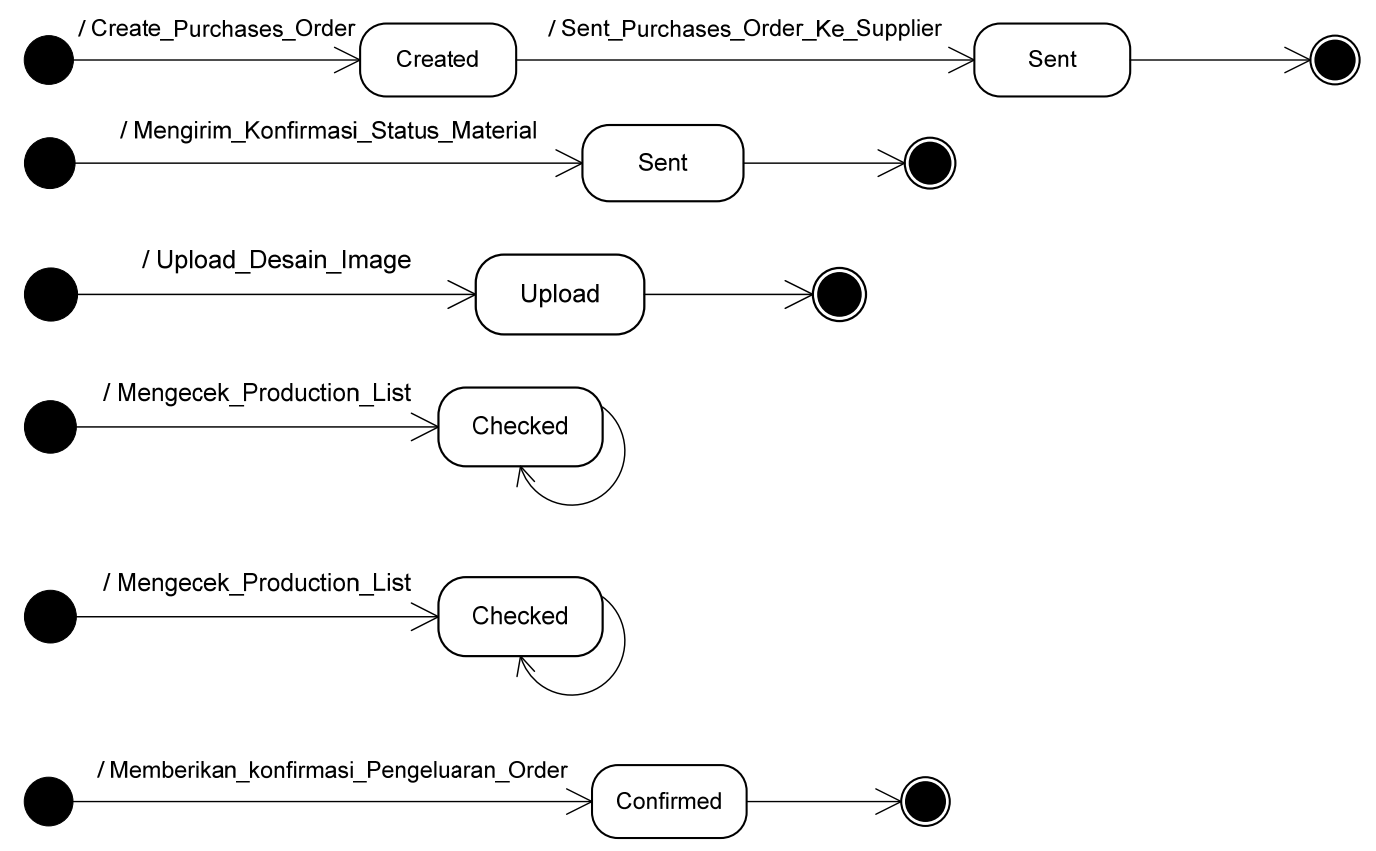

Gambar 16 State Chart Diagram

\section{Rancangan Layar}

Form Input Customer

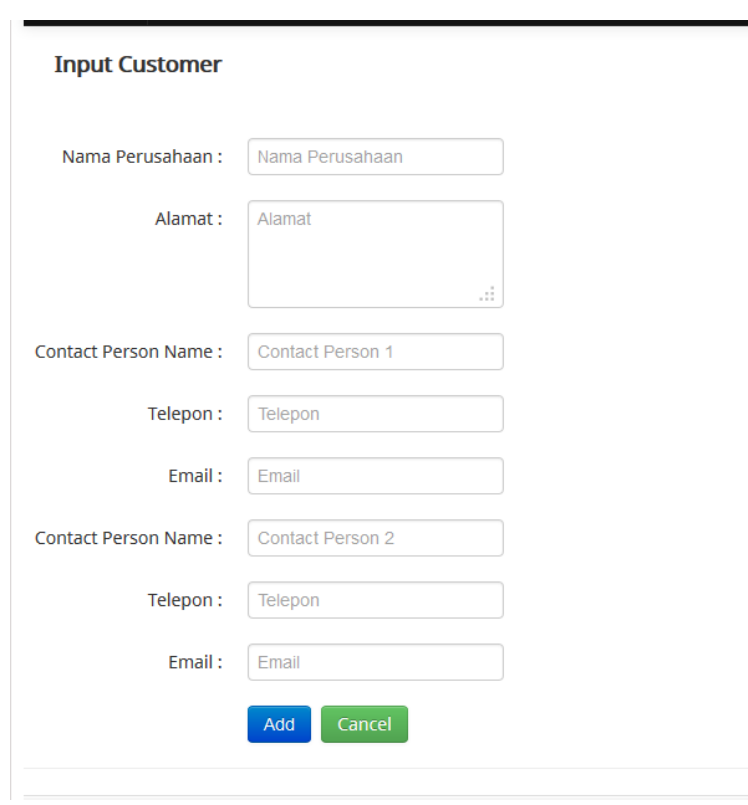

Gambar 17 Form Input Customer 


\section{Customer List}

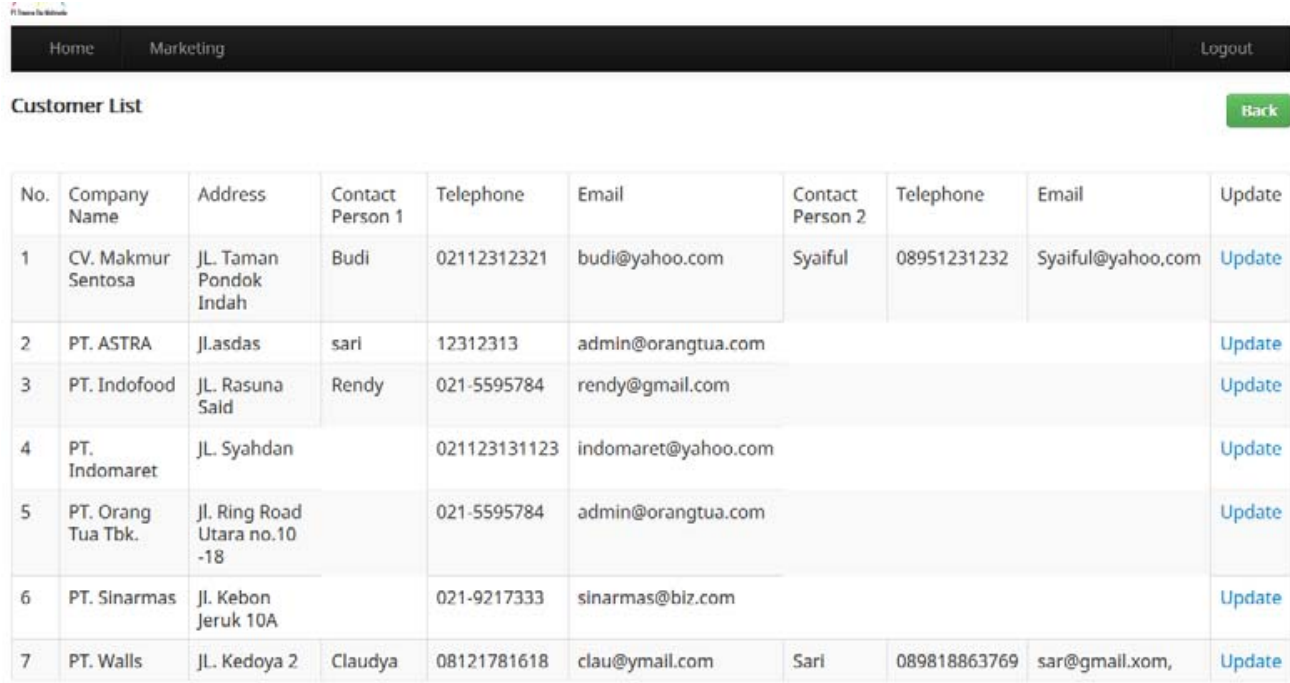

Gambar 18 Customer List

Purchase List

\section{ATriwarna Eka MultiMedia}

\begin{tabular}{|c|c|c|c|c|}
\hline \multicolumn{2}{|r|}{ Inventory } & & & Logout \\
\hline \multicolumn{5}{|c|}{ Purchase List } \\
\hline No. & Transaction ID & Supplier Name & Purchase Date & View \\
\hline 1 & 556677 & PT. Distro Kaos & $0000-00-00$ & Purchase Detail \\
\hline 2 & PJL/123123 & PT. King Garment & $0000-00-00$ & Purchase Detail \\
\hline 3 & PJL/KG2/13-4456 & PT. King Garment & $0000-00-00$ & Purchase Detail \\
\hline Back & & & & \\
\hline
\end{tabular}

Gambar 19 Purchase List

View Supplier

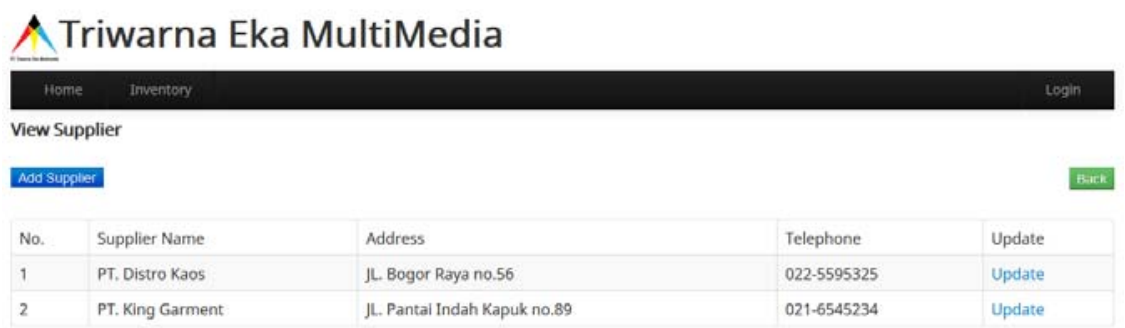

Gambar 20 View Supplier 
Stock List

\section{ATriwarna Eka MultiMedia}

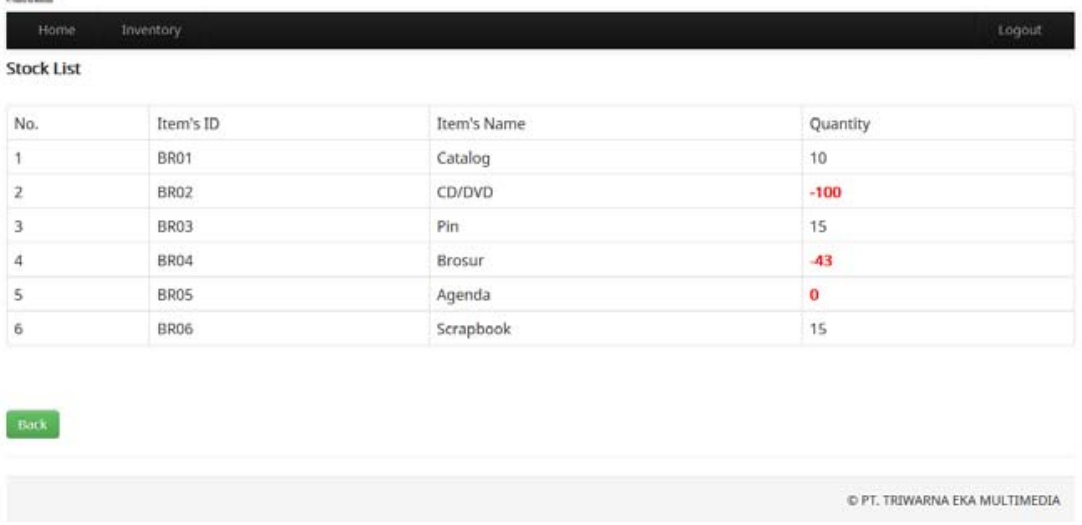

Gambar 21 Stock List

Production List

\section{ATriwarna Eka MultiMedia}

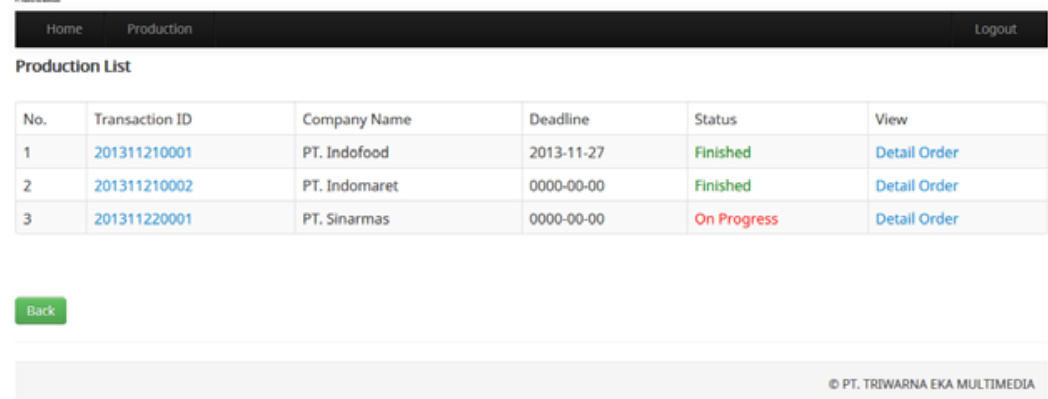

Gambar 22 Production List

Detail Order

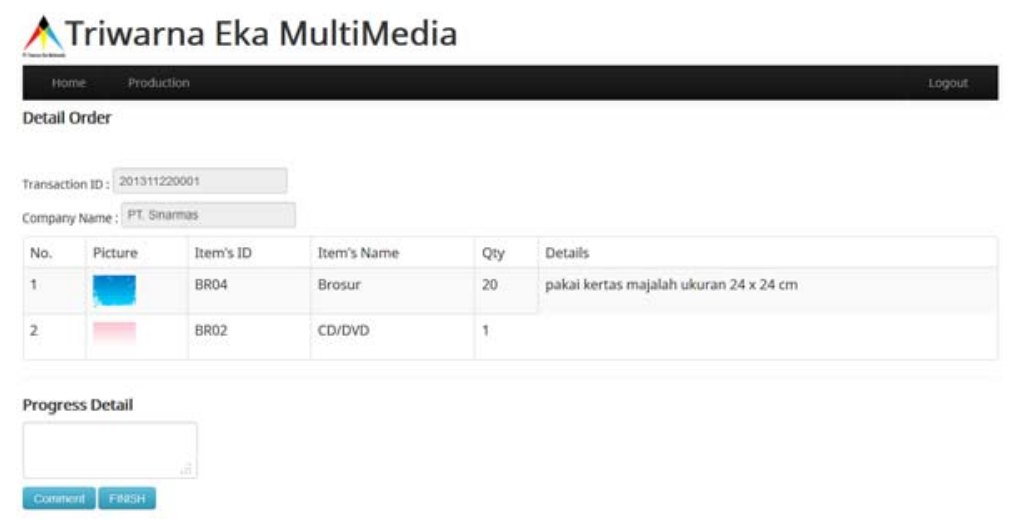

Gambar 23 Detail Order 


\section{SIMPULAN}

Setelah melakukan analisis dan perancangan dari proses bisnis PT Triwarna Eka Multimedia, disimpulkan bahwa: (1) Aplikasi sistem informasi berbasis internet yang diterapkan pada PT Triwarna Eka Multimedia memperbaiki penyimpanan record setiap proses bisnis yang terjadi di dalam PT Triwarna Eka Multimedia. (2) Dengan aplikasi sistem Informasi berbasis internet pada PT Triwarna Eka Multimedia akan mempermudah data untuk saling terintegrasi dari satu proses bisnis ke proses bisnis selanjutnya. (3) Aplikasi sistem Informasi pada PT Triwarna Eka Multimedia meminialisir terjadinya kehilangan data-data yang disebabkan oleh human error.

Saran yang dapat diberikan: (1) Melakukan control dan monitoring atas proses bisnis setelah menggunakan sistem informasi yang ada, menjaga agar sistem tersebut tetap dapat bekerja efektif dan efisien. (2) Training untuk user agar dapat menggunakan aplikasi secara optimal dan sesuai dengan fungsinya. (3) Sistem informasi harus di-update sesuai kebutuhan yang akan datang.

\section{DAFTAR PUSTAKA}

Alianto, H. (2011). Analisis Dan Perancangan Sistem Informasi Penjualan, Persediaan Dan Pembelian Pada Pt Xyz. Journal ComTech. 02(01): 532-538.

Bodnar, G. H., Hopwood, W. S. (2000). Sistem Informasi Akuntansi. Jilid 1, Edisi Keenam. Terjemahan Amir Abadi Jusuf \& Rudi M. Tambunan. Jakarta: Salemba Empat.

Chan, F., Qi, H. J. (2003). An innovative performance measurement method for supply chain management. Supply Chain Management: An International Journal. 8(3): 209-223.

Chen, I. J., Paulraj, A. (2004). Towards a theory of supply chain management: the constructs and measurements. Journal of Operations Management. 22(2): 119-150.

Hongren, C. T., Datar, S. M., Foster, G. (2003). Cost Accounting A Manajerial Emphasis. International Edition. 8th Edition. America: Prentice Hall.

Kotler, P., Kotler, K., Kelvin, L. (2006). Marketing Management. Singapore: Pearson Education.

Satzinger, J. W., Jackson, R. B., Burd, S. D. (2005). Object Oriented Analysis and Design with the Unified Process. USA: Course Technology.

Whitten, J. L., Bentley, L. D., Dittman, K. C. (2007). System Analysis and Design Methods $7^{\text {th }}$. McGraw-Hill Publishing.Co 